DOSSIÊ TEMÁTICO: Perspectivas para pensar as cidades: infâncias, educação, democracia e justiça

do] https://doi.org/10.22481/praxisedu.v16i40.6986

\title{
APRESENTAÇÃO DO DOSSIÊ TEMÁTICO: PERSPECTIVAS PARA PENSAR AS CIDADES: INFÂNCIAS, EDUCAÇÃO, DEMOCRACIA E JUSTIÇA
}

PRESENTATION OF THE THEMATIC DOSSIER: PERSPECTIVES TO THINK CITIES: CHILDHOOD, EDUCATION, DEMOCRACY AND JUSTICE

\author{
PRESENTACIÓN DEL DOSSIER TEMÁTICO: PERSPECTIVAS PARA PENSAR \\ CIUDADES: NIÑOS, EDUCACIÓN, DEMOCRACIA Y JUSTICIA
}

\begin{abstract}
PRESENTAZIONE DEL DOSSIER TEMATICO: PROSPETTIVE PER PENSARE LE CITTÀ: BAMBINI, EDUCAZIONE, DEMOCRAZIA E GIUSTIZIA
\end{abstract}

Marcia Aparecida Gobbi Universidade de São Paulo - Brasil

Cleriston Izidro dos Anjos Universidade Federal de Alagoas - Brasil

\begin{abstract}
Por isso, eis uma nova proposta: substituir o cidadão médio, adulto, masculino e trabalhador pela criança. Não se trata de realizar iniciativas, criar oportunidades e estruturas novas para as crianças, ou de defender os direitos de uma componente fraca da sociedade. Não se trata de modificar, actualizar ou melhorar os serviços para a infância, o que continua, evidentemente, a ser um dever importante da administração pública. Trata-se, sim, de baixar o ponto de vista da administração até à altura da criança, para não perder ninguém. Trata-se de aceitar a diversidade que a criança traz consigo como garantia de todas as diversidades. (TONUCCI, 2019, p. 60-61)
\end{abstract}

Cidades e infâncias, ampla temática que se abre a inúmeras reflexões, investigações e proposições em âmbitos acadêmico, político e educacional. Cientistas sociais, pedagogos e pedagogas e urbanistas têm buscado se debruçar em questões derivadas dessa junção que implica a relação entre crianças e espaços públicos e privados em nossas cidades, dentro e fora de instituições, não só escolares, e seus desdobramentos. 
Atualmente, estão se impondo todas as razões para se pensar de modo mais profundo e respeitoso sobre as crianças nas cidades. Embora sempre existentes, se não nos interpelavam com tamanha veemência tempos atrás, quando produzimos esse dossiê tornaram-se ainda mais gritantes, esgarçadas e vivas. Apresentam-se ao longo das transformações históricas que parecem não mudar, em especial no Brasil em que a violência e negligência do Estado e da elite estão amalgamadas e fazem-se presentes cotidianamente: são Agatha, João Pedro, Miguel, Jennifer, Kauã e tantas outras cujos nomes e modos de vidas desconhecemos. Propositadamente, essas crianças e jovens são anônimos e jogadas ao anonimato - à vala comum? - construído historicamente em nossas terras, sabendo que alguns são mais anônimos que outros.

A cada minuto temos motivos de sobra para pensar sobre as infâncias brasileiras que se fazem em cidades, em centros urbanos, mas também na roça, em sociedades indígenas, em quilombos. Crimes cometidos, em seus diferentes formatos, contra a população têm conferido às nossas cidades a triste face catastrófica da vida, traduzindo-se em catástrofes instaladas, tal como misérias que se arrastam há tempos, e outras em curso que nos mostram a sobreposição de misérias, implicando-se à violência, às lutas diárias. Mas, curiosamente, também produzem a vida presente e visível em fissuras, talvez quase imperceptíveis, ainda que esboçadas no fraco impulso de vida em alusão à canção de Caetano Veloso e que teimam estar lá, nos espaços de encontros e trocas, nas obras-cidades (LEFEBVRE, 2010) produzindo-as dentro dos limites impostos.

Estamos passando, em muitas cidades brasileiras, por aquilo que aqui denominamos de catástrofes - na saúde, na política, na educação - e ficamos nos perguntando sobre o que está sendo possibilitado como ações ou experiências citadinas para e com as crianças, em que elas sejam reconhecidas em todos os seus direitos. Como estão e se estão representadas atualmente nas políticas, como e se estamos construindo representações sobre as infâncias no Brasil nesse momento em diferentes compleições, inclusive entre as próprias crianças e o que tem restado de nós nesse momento. Quais crianças são hoje, representadas no âmbito das políticas públicas? Isso é fundamental discutir, mas também há que se preocupar em saber e reconhecer quais delas fazem parte de nossa construção de representações sobre as infâncias num momento perverso em que se mistura pandemia e catástrofe. Na ausência dessas crianças e na presença de outras tantas, e diante de um momento catastrófico, o que construímos e defendemos como sendo “crianças" e para quais cidades? Onde se apresentam? E onde estão representadas? Nas representações visuais, componentes fundamentais de mentalidades e práticas sociais, citamos 
aqui duas fontes de imagens: recentemente em cartaz que ilustra um programa político em que cinco crianças brancas apontam para o alto e sorriem para um país que existe para poucos ${ }^{1} \mathrm{e}$ contrastam com outras estampadas nas fotos de jornais que anunciam mais uns ou umas que saem do anonimato da pior e mais trágica maneira possível ${ }^{2}$. Caos, destruição e morte têm deixado seus rastros e não apenas em quadros e fotografias. Que testemunhos elas são ou deixam atualmente em suas vidas nas cidades? Nas palavras de Nestrovski e Seligman-Silva,

[...] a consciência da catástrofe modifica o nosso modo de perceber e representar, mas também de nos contrapor ao mundo. A exposição rotineira à violência talvez nos obrigue a aceitar, agora, a ampliação dos meios, e acatar o excesso como instrumento de sensibilização. (op. cit. 2000, p. 11).

Estamos conscientes dessas catástrofes instaladas e em curso que implicam as vidas das crianças? Isso nos aproxima ou afasta de pensamentos, práticas e pesquisas sobre as crianças nas cidades que abrigam ou desabrigam (?) crianças em suas mais distintas formas de vida e de disputas por manterem-se vivos? Parece-nos que há um excesso de exposição rotineira às catástrofes nossas de cada dia e vale refletir sobre as aceitações e existências construídas que originam, segundo nosso ponto de vista, as ausências das crianças, ou as presentificam de modos equivocados. Estão em tantos lugares, mas sempre determinadas a viver em nós e nas cidades de distintas formas.

Estamos escrevendo em junho de 2020. Sentimos uma cidade silente às crianças que gritam, ou nem conseguem chegar a isso, no estampido afirmado como perdido pelas ruas e dentro de suas casas. Iniciamos nossa apresentação com essas reflexões pois cremos que discutir sobre infâncias e cidades está implicado, ou deveria estar, a todas as crianças provocando pensar sobre como as representamos e estudamos em meio ao caos, e, quem sabe, quando estivermos fora dele. Acreditamos que nomear e escrever são formas de "erguer a voz" como diria bell hooks (2019), em suas palavras “É uma forma de reconhecer a força vital em todo objeto” (p.36) e que encontram-se também nas palavras escritas, daí organizá-las em alguns formatos, como um dossiê e trazer, ainda que brevemente, aspectos de uma catástrofe, que também envolve as crianças. Erguer a voz!

\footnotetext{
${ }^{1}$ Referência ao programa Pró-Brasil, lançado em 2020, pelo governo federal.

${ }^{2}$ Sobre isso sugiro que ouçam o podcast "em movimentos" número 15 , "Registros do que não foi escrito", em que Maria Cristina Stello Leite reflete sobre a questão. Pode ser encontrado nas plataformas soundclound e youtube. Coordenação do "em movimentos" de Marcia Aparecida Gobbi e edição de Beatriz Bitu Boss, numa produção coletiva de estudantes pesquisadoras do Grupo de Estudos e Pesquisas "Crianças, práticas urbanas, gênero e imagens" (CNPq/USP).
} 
Em 1991, o italiano Francesco Tonucci, dá início ao projeto "Cidades das Crianças", cuja proposta ampla e desafiadora é acreditar que as cidades podem ser transformadas a partir e com as crianças que nelas habitam. A tônica de sua ideia é que tempo e espaço, socialmente construídos, podem ser objeto de discussões e mudanças de políticas públicas urbanas e educacionais.

Há trinta anos suas reflexões soavam como revolucionárias e produziam inúmeras pesquisas e, inclusive, mais recentemente, a criação de outras "cidades das crianças", cujo mote é: pensar as crianças como paradigmas de cidades para todos. Entre as ideias de Francesco Tonucci, encontra-se a de pensar sobre a escola como local privilegiado para estabelecer discussões sobre a infância na cidade. Décadas atrás apresentou preocupações sobre a relação entre o espaço da escola e aquele produzido pela escola e que, como suas obras indicam, não dialogavam e ainda pouco o fazem. Sua proposta de escuta das crianças, que pode reverberar para os e as bebês, nos interpelam e provocam a pensar. Seguramente antes de Tonucci, questionamentos provocados pela presença das crianças em centros urbanos já existiam, muitos deles voltados para processos de higienização, que impunham a retirada das crianças pobres das ruas e a criação de legislações que justificassem atos espúrios dos próprios legisladores, entre outras questões. Porém, suas contribuições dão corpo e um belo pontapé inicial para estabelecer outras conversas e pontos de vista inéditos sobre esse assunto colocando a questão em outros patamares, sendo o direito a estar na cidade e frui-la em suas diferentes dimensões algo que acrescenta possibilidades inúmeras de pensar infâncias urbanas, essa temática que, em suas origens nem parecia robusta dados os confrontos nos quais se veria envolvida com outras áreas e suas compreensões sobre infâncias.

Tempos antes, a estadunidense Jane Jacobs, nos anos 1950, provocava a pensar numa cidade de gente, ou de pessoas, como podemos afirmar com base em sua obra. Sua obra traz um contributo importante para os estudos sobre crianças em espaços urbanos, embora não voltada diretamente à infância. Sua forma minuciosa de considerar o cotidiano e as relações nas cidades apresentava elementos que não percebemos a olhos nus e que se torna mais facilmente perceptível com olhares que estranham práticas sociais, sem esquecer das crianças. Ao olhar e tentar compreender o cotidiano, percebeu a calçada larga como local de encontro, de segregação, de passagem aligeirada dos pedestres e a elegeu como parte da cidade que merecia cuidados e reflexões. Entendeu as calçadas como lugar de crianças. É nela onde poderiam estar com outras crianças, nas imprevisibilidades da vida urbana, construindo a si e à própria cidade, diria Jacobs (2014). 
Não à toa optamos por marcar esse tempo, que parece estar um tanto distante. Ele é fundamental, em concordância ou discordância de suas propostas, vê-se hoje que elas apresentam deslocamentos nas maneiras como se conduzia a compreensão do que é ser criança e moradora de centros urbanos e a presença ou ausência de suas vozes, caladas ou escutadas. Faz-nos perceber as crianças em suas vidas nas cidades. É deste terreno que suas falas partem para nos provocar e têm frutos.

Importa-nos partir dessas reflexões iniciais, compreendidas dentro dos muitos limites impostos a uma apresentação de dossiê para e com elas, pensarmos sobre outros estudos que destacam essa temática provocando-nos a refletir sobre seu alargamento e a consideração de diferentes grupos infantis junto às pesquisas. Dando relevo à produção brasileira, não é possível esquecer da clássica pesquisa Trocinhas do Bom Retiro, de Florestan Fernandes, resultado de pesquisa realizado no final da primeira década do século XX na cidade de São Paulo, que nos traz compreensões sobre as crianças na cidade em seus bairros operários. Nos anos 1990, temos estudos que partem de preocupações sobre memórias, perspectivas, desejos e formas de deslocamentos aprendidos e vividos por crianças em situação de rua na cidade do Rio de Janeiro, e que trata de uma insurreição juvenil e de crianças presentes nas investigações apresentadas no livro "Vozes do meio fio" (SILVA e MILITO, 1994). "Viração: Experiencias de meninos de rua", deriva de pesquisa com crianças, também em situação de rua, na cidade de São Paulo, estudo realizado entre 1991-1995, (GREGORI, 2000) em que a extrema desigualdade social brasileira e presente nos grandes centros urbanos, paulistano, dos chamados "meninos e meninas de rua", interessa para nosso estudo e breve exposição. Sua investigação desmonta certa compreensão vigente de que, para essas crianças, estar nas ruas é sinônimo de abandono. Ao estar com as crianças, prática fundamental para conhecê-las, a autora não apenas mostra a "viração" como prática de vida, mas o prazer de estar com os amigos e amigas nas ruas. Se a rua é espaço de encontro e troca (LEFEBVRE, 2013) essas meninas e meninos nos mostram outras dimensões de práticas presentes em vidas ambíguas, conflituosas que também constroem formas de proteção e cuidado, o que não quer dizer dispensar a garantia de direitos. Não é o caso aqui aprofundar estas temáticas, trata-se apenas de uma breve provocação, contudo, não podemos deixar de compreender com esses estudos, outras formas de viver e fazer a cidade pelas crianças e implicações necessárias para a compreensão do tema de grande amplitude: infâncias e cidades. De modo concomitante, os estudos sociais da infância, em especial a antropologia e a sociologia, conjugados com estudos educacionais e urbanos, colocam a lume a urgência de se ouvir as crianças também nas cidades, não somente nas 
creches, pré-escolas e escolas. Trata-se de tema em desenvolvimento, cujo ponto de partida tem como referência as ciências sociais, em especial a sociologia urbana (MULLER e NUNES, 2014). Com base em seus estudos, a autora e o autor creditam aos espaços públicos a capacidade de certa redução das distâncias sociais (p.671), compreensão da qual resultarão investigações, inclusive dos próprios autores concernentes a preocupação sobre mobilidade urbana e as crianças.

A educação ao dialogar sobretudo com a arquitetura apresentou importantes reflexões, porém, intermitentes, especialmente inauguradas por Mayumi Souza Lima, que recupera a preocupação com o diálogo possível entre escola e cidade, tão apartadas, em seu livro “A criança e a cidade" (1989). A autora emprega uma prática ainda nem tão frequente, ou não tanto quanto poderia, que é a escuta da criança sobre os lugares vividos nas escolas frequentadas, impulsionando, a partir delas, outras formas de relação entre escola, crianças e cidade. $\mathrm{O}$ desenho é a linguagem que lhe serve de recurso para estabelecer, não apenas o diálogo com as crianças, como também para documentar e refletir sobre os registros imagéticos criados acerca das escolas frequentadas e uma delas se destaca no projeto com as crianças, a Escola Estadual João Kopke, situada na região central de São Paulo, SP. Destaca-se a preocupação com espaços estimulantes à imaginação, como também, a participação de estudantes nos processos decisórios da escola, cuja relação com a rua ganhava destaque na construção das relações entre os espaços público e privado.

Por enquanto, interessa-nos apenas enfatizar que tais pesquisas tornaram-se referências para outros estudos, inclusive alguns que compõem esse dossiê. São muitos os caminhos percorridos e ainda a percorrer quando nos debruçamos sobre os estudos que envolvem infâncias e cidades. Compreender as conexões existentes entre eles, suas influências e desdobramentos, as reflexões possíveis e agora um leque mais amplo de compreensões oriundas de uma mesma temática orienta parte dos artigos apresentados nesse dossiê. Retomamos apenas as reflexões iniciais e recolocamos questões: quando o assunto é infâncias e cidades onde estão as crianças e como são representadas em nossas vidas, em nossas pesquisas? Entre camadas de catástrofes e considerando as atualmente vividas em nosso país que histórias nos contam as crianças pelas ruas ou longe delas, com teto ou sem ele, em praças e jardins? Como têm sobrevivido e quais marcas deixam? Nas relações que estabelecemos com elas que representações criamos e quais pautam nossos modos de compreendê-las? Mas, ainda fica a pergunta sobre quais crianças considerar, quais são representadas e por quais nos enlutamos, 
nos alegramos, paramos para cumprimentar, fazer um agrado, vimos ou deixamos de ver quando estão nas cidades.

O dossiê "Perspectivas para pensar as cidades: infâncias, educação, democracia e justiça” tem como objetivo reunir e compartilhar análises e estudos a partir de relações diretas e indiretas das crianças de 0 a 10 anos com as cidades. Procuramos reunir perspectivas que nos permitam pensar que possíveis lugares as crianças (não) têm ocupado em tantas cidades do Brasil e fora dele, bem como os modos pelos quais as crianças são vistas ou representadas em diferentes contextos sociais. Partindo do princípio de que as crianças têm direitos, incluindo o direito à participação nos processos sociais com voz e vez, nos interessa pensar em que medida esses direitos (não) têm sido respeitados, bem como quais são os possíveis mecanismos que garantem ou inviabilizam a presença de meninas e meninos nas cidades.

Considerando ainda o fato de que o direito à cidade implica o acesso a ela de modo mais amplo, incluindo à participação de processos decisórios e de criação da própria cidade, é possível questionar: que experiências as cidades têm proporcionado às crianças desde bebês? Elas são consideradas como produtoras dos espaços das cidades? Que problematizações, inquietações e proposições os campos teóricos que tem contribuído com os estudos das infâncias, podem apontar para pensarmos a participação democrática das crianças nas cidades?

Concebido com o objetivo de fomentar reflexões sobre os diferentes usos dos espaços da cidade pelas crianças em contextos diversos, incluindo formas de viver e lutar por moradias e outros direitos, dentre os quais, o direito de brincar, de explorar as ruas, parques e praças e de participação nas mais diversas atividades culturais e políticas que envolvem a cidade, especialmente quando se tratam de crianças em contextos de múltiplas invisibilidades e segregações, provocados por diversos marcadores - a saber, idade, étnico, classe social, gênero e raça - interessa-nos contribuir para a mobilização de um debate que nos permita pensar nos entraves e perspectivas da garantia dos direitos das crianças, especialmente no que se trata aos modos por meio dos quais as crianças participam, interferem e produzem sentidos nos contextos e cotidianos dos quais participam, a partir das interações entre adultos e crianças e das crianças entre si nos diversos espaços e instituições das cidades.

No primeiro artigo - intitulado "Normas éticas traduzem-se em ética na pesquisa? Pesquisas com crianças em instituições e nas cidades", partindo da constatação do aumento de pesquisas brasileiras que citam normas éticas nas pesquisas com crianças nas instituições e nas cidades, Renata Lopes Costa Prado (Universidade Federal Fluminense, Brasil) e Marcos Cezar de Freitas (Universidade Federal de São Paulo, Brasil), problematizam se este aumento da 
presença efetivamente se traduz em pesquisas orientadas por estes princípios que buscam não somente proteger os/as participantes de nossas investigações, mas como algo que orienta o pensar e o fazer ciência, ou seja, com questões que, para além do uso de métodos e de técnicas adequadas, preocupa-se com os interesses humanos e coletivos. Após a análise de um conjunto de artigos e de teses e dissertações que relatam pesquisas com crianças nos campos da antropologia, da sociologia, da psicologia e da educação, a autora e o autor constatam que parcela significativa dos relatos, apenas mencionam os cuidados considerados como necessários para aprovação em instâncias éticas sem, no entanto, trazer uma discussão mais aprofundada sobre os desafios e dilemas éticos do fazer pesquisa com crianças.

No segundo artigo, intitulado "Escola da infância, cidade e democracia: em busca do exercício da cidadania infantil", Fabiana de Oliveira Canavieira (Universidade Federal do Maranhã, Brasil) e Olivia Pires Coelho (Universidade Estadual de Campinas, Brasil), tendo como objetivo evidenciar concepções que fomentam a participação das crianças desde bebês nas cidades, por meio da relação entre as instituições de Educação Infantil e demais espaços públicos, as autoras apresentam uma discussão articulada sobre educação das crianças, visibilidade e garantia do direito às cidades. As autoras apontam para possibilidades de territorialização das crianças no espaço urbano como alternativa para o exercício da democracia e da cidadania das crianças, com destaque para o papel das instituições de Educação Infantil nesse movimento. Discutem, ainda, a concepção de território educativo no contexto da Educação Infantil paulistana e a importância da intencionalidade político-pedagógica sustentada em princípios democráticos como forma de garantia do direito à cidade para todas as crianças.

No terceiro artigo ${ }^{3}$, intitulado "Redistribuição, reconhecimento e representação: uma leitura de Nancy Fraser com um olhar infantil”, partindo do princípio de que as crianças são excluídas das discussões gerais sobre o significado da justiça, sendo a elas delegado o lugar de expectadora e não de partícipe das políticas para a infância, Lourdes Gaitán Muñoz (Associação Grupo "Sociologia da Infância e da Adolescência", Espanha), apresenta contributos para uma reflexão sobre a justiça como concepção coerente aos pressupostos da sociologia da infância na medida em que esta defende e exige o reconhecimento das crianças como capazes e com direitos

\footnotetext{
${ }^{3}$ Publicado em espanhol e em língua portuguesa (tradução livre do original).
} 
à benefícios sociais para elas mesmas. Para essa discussão, a autora se baseia nas contribuições de Nancy Fraser ${ }^{4}$ para discutir a proficuidade do lugar das crianças em relação à justiça.

No quarto artigo, intitulado "O cotidiano lúdico dos engraxates paulistanos", André Augusto de Oliveira Santos (Universidade de São Paulo, Brasil) e José Geraldo Vinci de Moraes (Universidade de São Paulo, Brasil), relatam o trabalho de engraxates de diferentes idades - incluindo infâncias trabalhadoras - da cidade de São Paulo, SP, que desde o século XIX, constroem o cotidiano da cidade por meio do trabalho ambulante. A luta humana cotidiana nas ruas de São Paulo como forma de conseguir algum recurso que lhes possibilite à manutenção da vida, encontra algum respiro na ludicidade vivida nos jogos, nas brincadeiras e nas batucadas que se davam nas brechas do tempo de atendimento entre um cliente e outro. Por meio de fontes diversas - periódicos, fotografias, documentos - os autores apresentam elementos cotidianos do passado e do presente do uso dos espaços públicos pelos engraxates na cidade de São Paulo, com seu jeito de ganhar algum dinheiro em um contexto permeado pela disputa pela sobrevivência, seja pelo desemprego, pela violência ou por outros tantos fatores excludentes. Em meio à lida cotidiana, há que se encontrar "respiros" que nos permitam seguir caminhando.

No quinto artigo, intitulado "Os jardins/parques urbanos de Lisboa pelo olhar de adultos e pela ação das crianças", partindo de uma investigação etnográfica construída por meio da observação participante e da realização de entrevistas qualitativas realizadas com frequentadores de dois parques públicos de Lisboa - e recorrendo aos estudos da Sociologia Urbana e da Sociologia da Infância, Eunice Castro Seixas (Universidade de Lisboa, Portugal), Catarina Tomás (Instituto Politécnico de Lisboa, Portugal) e Niccolò Giacchetta (Universidade IUAV de Veneza, Itália), procuram dar visibilidade às crianças como produtoras de conhecimento diferenciados dos adultos, discutindo a situação da infância na cidade como forma de pensar o social. As autoras e o autor apontam para o fato de que estes espaços geralmente são pensados sem a participação das crianças, mas numa série de representações que se tem sobre elas e isso traz implicações para a agência e as práticas socioespaciais das crianças que se apropriam dos espaços e efetivam seu direito à cidade.

No sexto artigo, intitulado "Infâncias e o direito à cidade em São Gonçalo: investigando a participação de crianças na cidade”, Maria Tereza Goudard Tavares (Universidade do Estado

\footnotetext{
4 Teórica crítica feminista norte-americana, as obras de Nancy Fraser apresentam diversas contribuições para os debates sobre democracia, justiça, feminismo e políticas afirmativas, dentre outros temas.
} 
do Rio de Janeiro, Brasil) apresenta parte dos resultados de uma pesquisa ${ }^{5}$ mais ampla. Para a autora, a cidade é um campo de práticas infantis de conhecimento, de leituras, de representação e apropriação do espaço urbano.

No sétimo artigo, intitulado "Sediciosas formas de viver: crianças, arte e cozinha na luta pelo direito à moradia”, Marcia Aparecida Gobbi (Universidade de São Paulo, Brasil), Cleriston Izidro dos Anjos (Universidade Federal de Alagoas, Brasil) e Juliana Diamente Pito (Núcleo de Educação Infantil Paulistinha da Universidade Federal de São Paulo, Brasil), também a partir de parte dos dados de uma pesquisa ${ }^{6}$ mais ampla, refletem a respeito dos encontros vividos dentro da Ocupação 9 de julho, que ocorrem mensalmente aos domingos, bem como sobre um encontro para crianças realizado no Ocupação Mauá, localizados na região central da cidade de São Paulo, SP. Para as autoras e o autor, a presença das Ocupações e suas atividades artísticas e sociais contribuem com os processos de transformação do entorno, alterando os modos de lidar e de viver nos locais em que estão localizadas, contribuindo também para repensarmos formas de luta que impulsionam reflexões sobre a crise social e política corrente, para além da luta por moradia, e implicam pensar e aprender sobre estratégias possíveis para criar novas formas de governar. O texto se divide em dois momentos - arte e comida - em que mulheres e crianças se encontram, configuram e constroem formas de lutar pelo direito à moradia e à cidade, revelando aquelas e aqueles que sofrem constantes processos e tentativas de silenciamento e de exclusão.

No oitavo artigo ${ }^{7}$, intitulado "O direito de brincar: uma necessidade para as crianças, uma potencialidade para a escola e a cidade", Francesco Tonucci (Instituto de Ciências e Tecnologias da Cognição - ISTC - Conselho Nacional de Pesquisa), nos apresenta a brincadeira como fundamental para a discussão sobre as políticas urbanas, incluindo reflexões sobre a formas de organização urbana e as diferentes compreensões sobre participação das crianças na cidade. $\mathrm{O}$ autor apresenta reflexões sobre práticas existentes de cidades que contemplam o ponto de vista das crianças como paradigma.

Tonnuci, também conhecido como Frato, é educador, psicopedagogo e cartunista reconhecido internacionalmente por ser um defensor dos direitos das crianças. Seus livros e outros textos e suas produções visuais nos trazem profundas reflexões, especialmente para

\footnotetext{
${ }^{5}$ As infâncias e a cidade: investigando componentes territoriais de processos educativos de crianças das classes populares na cidade de São Gonçalo.

${ }^{6}$ Imagens de São Paulo: moradia e luta em regiões centrais e periféricas da cidade a partir de representações imagéticas criadas por crianças.

${ }^{7}$ Artigo publicado em italiano e em língua portuguesa (tradução livre do original).
} 
pensar a cidade à partir das crianças e com elas. Seu projeto “A cidade das crianças”, realizado na cidade de Fano (Itália), desde 1991, em que a criança é o centro para pensar a cidade é, inegavelmente, uma inspiração para os/as que se preocupam com os direitos das crianças e se colocam à disposição para pesquisar, pensar e construir uma cidade melhor para todos e todas, desde bebês.

Por fim, no nono artigo, trazemos uma conversa ${ }^{8}$ de Marcia Aparecida Gobbi (Universidade de São Paulo, Brasil) com Ana Barreiro e África Martinez, arquitetas responsáveis pela Associação "Taller Abierto", na cidade de Pontevedra, Espanha, que atuam em conjunto com o município, considerado como uma "cidade das crianças". A transcrição dessa conversa, fruto do desejo de conhecer e aprender com cidades das crianças e quem contribui para que se materializem em práticas e reflexões, deveu-se ao intento de provocar e continuar debates sobre o tema, considerando as particularidades de cada país e das crianças que neles vivem. Ao considerar o ponto de vista das crianças precisamos contemplar a todas elas.

Reiteramos que este dossiê foi concluído em meio ao um complexo cenário de pandemia que, no Brasil, se soma a outros problemas políticos e sociais. Assim, registramos que esta produção só foi possível por um esforço coletivo de autoras e de autores do Brasil e do exterior e com o apoio da equipe da revista Práxis Educacional (Universidade Estadual do Sudoeste da Bahia, Brasil) e dos homens e mulheres participantes de nossos grupos de pesquisa, a saber: o Grupo de Estudos e Pesquisas "Crianças, práticas urbanas, gênero e imagens" (CNPq/FE/USP) e o GEPPECI - Grupo de Estudos e Pesquisas em Pedagogias e Culturas Infantis (CNPq/CEDU/UFAL). Elas e eles nos mantém firmes na certeza de que gente foi feita para brilhar e não para morrer de fome, parafraseando Caetano Veloso, e ainda, parafraseando os Titãs, a gente quer comida, diversão, arte... a gente quer inteiro (e para todos e todas, desde bebês) e não pela metade.

Sigamos!

\section{REFERÊNCIAS}

FERNANDES, Florestan. As Trocinhas do Bom Retiro. IN: Folclore e Mudança Social na Cidade de São Paulo. São Paulo: Editora Martins Fontes, 2004.

GREGORI, Maria Filomena. Viração: experiencias de meninos de rua. São Paulo: Editora Companhia das Letras,

\footnotetext{
${ }^{8}$ Entrevista originalmente realizada em espanhol com tradução para a língua portuguesa.
} 
HOOKS, Bell. Erguer a voz: pensar como feminista, pensar como negra. São Paulo: Editora Elefante, 2019.

JACOBS, Jane. Morte e vida nas grandes cidades. São Paulo: Editora Martins Fontes, 2014

LEFEBVRE, Henri. La producion del espacio. Espanha: Editora Capitain Swing, 2013.

LEFEBVRE, Henri. O direito à cidade. São Paulo: Editora Record, 2010

LIMA, Mayumi Souza. A cidade e a criança. São Paulo: Nobel, 1989

MULLER, Fernanda; NUNES, Brasilmar Ferreira. Infância e cidade: um campo de estudo em desenvolvimento. Educ. Soc., Campinas, v. 35, nº. 128, p. 629-982, jul.-set., 20146

NESTROVSKI, Artur; SELIGMAN-SILVA, Marcio. (Org.). Catástrofe e Representação. São Paulo: Editora Escuta, 2000.

SILVA, Hélio; MILITO, Claudia. Vozes do meio fio. Rio de Janeiro: Editora Relume \& Dumará, 1994.

TONUCCI, Francesco. A cidade das crianças: um novo modo de pensar a cidade. Francesco Tonucci / Tradução: Margarida Periquito. Matosinhos: Ágora K, 2019. (Título Original: La città dei bambini, de Francesco Tonucci, 1996).

\section{ORGANIZADORA E ORGANIZADOR:}

\section{Marcia Aparecida Gobbi}

Possui Doutorado em Educação pela Universidade Estadual de Campinas. Professora da Faculdade de Educação da Universidade de São Paulo, atuando nos cursos de Licenciatura em Ciências Sociais e de Pedagogia e junto ao Programa de Pós-Graduação em Educação. Atualmente dedica-se a investigar representações e criações da infância em luta por moradia em ocupações na cidade de São Paulo. Coordenadora do Grupo de Estudos e Pesquisas "Crianças, práticas urbanas, gênero e imagens" (CNPq/FE/USP). E-mail: mgobbi @usp.br

iD http//orcid.org/0000-0001-9850-01901

\section{Cleriston Izidro dos Anjos}

Possui Doutorado em Educação pela Universidade Federal de Alagoas. Professor do Centro de Educação da Universidade Federal de Alagoas, Membro do Corpo Docente do Mestrado em Educação Pré-Escolar da Universidade Katyavala Bwila (Angola), Membro Colaborador Doutorado do Centro de Investigação em Estudos da Criança da Universidade do Minho (Portugal) no grupo "Contextos, quotidianos e bem estar da criança". Atua principalmente nos seguintes temas: Educação Infantil, Formação Docente, Linguagens Expressivas e Culturas das Infâncias. Coordenador do GEPPECI - Grupo de Estudos e Pesquisas em Pedagogias e Culturas Infantis (CNPq/CEDU/UFAL). E-mail: cianjos@yahoo.com.br

iD http://orcid.org/0000-0003-1040-4909 